\title{
DÜBLIN
}

Technological University Dublin

ARROW@TU Dublin

\section{The Anti-Microbial Efficacy of Plant Essential Oil Combinations and Interactions with Food Ingredients}

Jorge Gutierrez

Technological University Dublin, Jorge.Gutierrez@tudublin.ie

\section{Catherine Barry-Ryan}

Technological University Dublin, Catherine.Barryryan@tudublin.ie

Paula Bourke

Technological University Dublin, paula.bourke@tudublin.ie

Follow this and additional works at: https://arrow.tudublin.ie/schfsehart

Part of the Food Microbiology Commons

\section{Recommended Citation}

Gutierrez, J., Barry-Ryan, C. \& Bourke, P. (2008) The anti-microbial efficacy of plant essential oil combinations and interactions with food ingredients. International Journal of Food Microbiology, Vol, 124, Issue 1, 10 May 2008, Pages 91-97. doi:10.1016/j.ijfoodmicro.2008.02.028

This Article is brought to you for free and open access by the School of Food Science and Environmental Health at ARROW@TU Dublin. It has been accepted for inclusion in Articles by an authorized administrator of ARROW@TU Dublin. For more information, please contact arrow.admin@tudublin.ie, aisling.coyne@tudublin.ie, gerard.connolly@tudublin.ie.

Funder: Irish Department of Agriculture and Food as part of the National Development Plan 2000-2006.

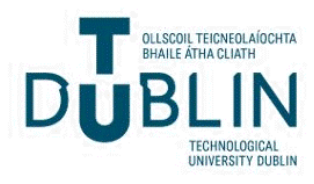



and interactions with food ingredients"

21 Running Title: Antimicrobial efficacy of plant EOs and interactions with food

22 ingredients 


\section{Abstract}

2 The objective of this study was to evaluate the efficacy of plant essential oils (EOs) in 3 combination and to investigate the effect of food ingredients on their efficacy. The EOs

4 assessed in combination included basil, lemon balm, marjoram, oregano, rosemary, sage

5 and thyme. Combinations of EOs were initially screened against B. cereus, E. coli, L.

6 monocytogenes and $P$. aeruginosa using the spot-on-agar test. The influence of varying

7 concentrations of EO combinations on efficacy was also monitored using E. coli. These

8 preliminary studies showed promising results for oregano in combination with basil,

9 thyme or marjoram. The checkerboard method was then used to quantify the efficacy of

10 oregano, marjoram or thyme in combination with the remainder of selected EOs.

11 Fractional inhibitory concentrations (FIC) were calculated and interpreted as synergy,

12 addition, indifference or antagonism. All the oregano combinations showed additive

13 efficacy against B. cereus, and oregano combined with marjoram, thyme or basil also had

14 an additive effect against $E$. coli and $P$. aeruginosa. The mixtures of marjoram or thyme

15 also displayed additive effects in combination with basil, rosemary or sage against $L$.

16 monocytogenes. The effect of food ingredients and $\mathrm{pH}$ on the antimicrobial efficacy of

17 oregano and thyme was assessed by monitoring the lag phase and the maximum specific

18 growth rate of L. monocytogenes grown in model media. The model media included

19 potato starch $(0,1,5$ or $10 \%)$, beef extract $(1.5,3,6$ or $12 \%)$, sunflower oil $(0,1,5$ or

$2010 \%$ ) and TSB at pH levels of 4, 5, 6 or 7 . The antimicrobial efficacy of EOs was found

21 to be a function of ingredient manipulation. Starch and oils concentrations of 5\% and $10 \%$

22 had a negative impact on the EO efficacy. On the contrary, the EOs were more effective

23 at high concentrations of protein, and at $\mathrm{pH}$ 5, by comparison with $\mathrm{pH} 6$ or 7 . This study 
1 suggests that combinations of EOs could minimize application concentrations and

2 consequently reduce any adverse sensory impact in food. However, their application for

3 microbial control might be affected by food composition, therefore, careful selection of

4 EOs appropriate to the sensory and compositional status of the food system is required.

5 This work shows that EOs might be more effective against food-borne pathogens and

6 spoilage bacteria when applied to ready to use foods containing a high protein level at

7 acidic $\mathrm{pH}$, as well as lower levels of fats or carbohydrates.

9 Key words: essential oils, antimicrobial, synergy, food ingredients, food application 


\section{Introduction}

2 Essential oils (EOs) are aromatic and volatile oily liquids obtained from plant material.

3 They are normally formed in special cells or groups of cells, found in leaves and stems,

4 and commonly concentrated in one particular region such as leaves, bark or fruit

5 (Oussalah et al., 2006). Although the antibacterial properties of EOs have been long

6 recognized, the recent interest in alternative naturally derived antimicrobials has lead to a

7 renewed scientific interest in these substances. Many in vitro studies report a high

8 efficacy of EOs against food-borne pathogens and spoilage bacteria (Smith-Palmer et al.,

9 1998; Hammer et al., 1999; Elgayyar et al., 2001; Dorman and Deans, 2002). However, a

10 higher concentration of EO is needed to achieve the same effect in food as in vitro (Burt,

11 2004). If EOs are expected to be widely applied as antibacterials, the organoleptical

12 impact should be considered as the use of naturally derived preservatives can alter the

13 taste of food or exceed acceptable flavour thresholds (Hsieh et al., 2001; Nazer et al.,

14 2005). Thus, combinations of plant extracts may help to minimise concentrations and

15 consequently reduce sensory impact. Furthermore, these combinations may also control

16 some bacteria that are known to show consistently high resistance to plant antimicrobials,

17 such as Pseudomonas spp. (Hammer et al., 1999; Holley and Patel, 2005). Although

18 some studies have concluded that whole EOs have a greater antibacterial activity than the

19 major components mixed (Gill et al., 2002; Mourey and Canillac, 2002), the combination

20 of these major components with other components that have a weaker activity can

21 achieve a synergistic effect (Ultee et al., 2000).

22 In general, the efficacy of many added and naturally occurring antimicrobials may be

23 reduced by certain food components (Glass and Johnson, 2004). It is supposed that high 
1 levels of fat and/or protein in foodstuffs protect bacteria from the action of EOs (Aureli et

2 al., 1992; Pandit and Shelef, 1994; Tassou al., 1995). Carbohydrates in foods do not

3 appear to protect bacteria from the antimicrobial effects of EOs (Shelef et al., 1984). Gill

4 et al. (2002) suggested that the greater availability of nutrients in foods compared to

5 laboratory media may enable bacteria to repair damaged cells faster. In this respect not

6 only the intrinsic properties of the food are important but extrinsic determinants, such as

7 temperature or characteristics of bacteria, can affect bacterial sensitivity (Burt, 2004).

8 Since most foods are mainly composed of water, carbohydrates, fats, proteins and $\mathrm{NaCl}$,

9 it is important to analyse the influence of these components on the antimicrobial activity

10 of any proposed antimicrobial compound (Devlieghere et al., 2004).

11 Recent studies have shown that plant extracts are useful for reduction of pathogens

12 associated with chicken frankfurters (Mytle et al., 2006) or cooked beef (Ahn et al.,

13 2007). On the contrary, some authors recorded very low antimicrobial activity or no

14 effect against E. coli $\mathrm{O} 157: \mathrm{H} 7$ or Salmonella when EOs were applied to ground beef

15 (Uhart et al., 2005) or ready-to-cook chicken (Firouzi et al., (2007), respectively. The

16 application of plant EOs for control of foodborne pathogens and food spoilage bacteria

17 requires the evaluation of a number of aspects; the effects on organoleptic properties,

18 evaluation of the range of activity against the organisms of concern to a particular

19 product as well as food compositional effects on activity. Optimal application in real food

20 systems depends on these factors, therefore, the application of EOs in food should

21 incorporate studies to determine and quantify the effect of food ingredients on their

22 antimicrobial activity. This work aims to bridge in vitro studies with practical application

23 of EOs through assessing the effects of a range of concentrations of main food 
1 components based on meat and vegetable substrates prior to application in complex food

2 systems. Thus, the objectives of this study were to evaluate and quantify the effect of a

3 range of plant EOs in combination, against four pathogens, B. cereus, E. coli, L.

4 monocytogenes and $P$. aeruginosa, and to determine interactive effects with protein,

5 carbohydrate, oil and $\mathrm{pH}$ levels in order to optimise applications in food.

6

7 2. Material and methods

$8 \quad$ 2.1. Essential oils

9 The essential oils (EOs) selected for this study and their composition are indicated in

10 Table 1. The selection was based on a balance between reported antimicrobial efficacy,

11 sensory properties and presence of different components in the EOs. The EOs were

12 obtained from Guinness Chemical Ltd. (Portlaoise, Ireland) and were $\mathrm{CO}_{2}$ soluble SE-

13 extracts from leaves.

14

\section{2.2. Bacteria}

16 The bacteria used in this study were Bacillus cereus ATCC 11778, Escherichia coli 17 ATCC 25922, Listeria monocytogenes IL323 and Pseudomonas aeruginosa ATCC

18 27853. The product isolated Listeria strain was kindly provided by the Department of

19 Life Sciences, University of Limerick, Ireland. All cultures were maintained at $-70^{\circ} \mathrm{C}$ in

$2020 \%$ glycerol and grown in Tryptic Soy Broth (TSB, pH 7.2, Scharlau Chemie) at $37^{\circ} \mathrm{C}$

21 for 24 hours to obtain sub-cultures. Working cultures were prepared from sub-cultures

22 and grown under optimal conditions for each bacterium for 18 hours. Working cultures 
1 were adjusted to the required concentration of $10^{6} \mathrm{CFU} / \mathrm{ml}$ using the McFarland standard

2 (Biomerieux Inc.).

$4 \quad$ 2.3. Synergy studies

5 Combinations of EOs were qualitatively assessed using the spot-on-agar test. The

6 effect of varying concentrations on efficacy of EO combinations was determined using $E$.

7 coli ATCC 25922 as a test organism. Fractional inhibitory concentration (FIC) indices

8 were calculated using the checkerboard method to quantify the potential synergy of

9 oregano, marjoram or thyme in combination with the remainder of selected EOs. Assays

10 were performed in duplicate and then replicated.

\section{2.3.1. Spot-on-agar test}

13 The spot on agar test was performed based on previous work (Cintas et al., 1998) but 14 with modifications. Ten $\mu$ of EO extracts diluted in ethanol at $10 \%(\mathrm{v} / \mathrm{v})$ were spotted 15 onto TSA $(1.2 \%)$ plates seeded with $10^{6} \mathrm{CFU} / \mathrm{ml}$ of the indicator strain. Combinations 16 were initially assessed in a 1:1 ratio. Spotted plates were then incubated at $37^{\circ} \mathrm{C}$ for $18 \mathrm{~h}$.

17 Ethanol was used as control and inhibition zones around the wells were measured in 18 millimetres.

20 2.3.2. Effect of varying concentrations on efficacy of EO combinations against E. coli

21 The influence of varying concentration of EO combinations on efficacy was assessed

22 against E. coli using 96-well micro titer plates (Sarstedt Ltd). The first row of each plate 23 contained $100 \mu \mathrm{l}$ of the EO extract or the EO combination (1:1) diluted in TSB. The range 
1 of initial concentrations for each of the EOs is indicated in Table 2. Wells containing

2 EOs in the first row were then diluted two fold along each column. At least 2 columns

3 were used for controls. Positive controls contained growth media inoculated with the

4 organism under investigation. Negative controls contained EOs and sterile growth media

5 only. Finally, $100 \mu \mathrm{l}$ of media containing $2 \times 10^{6} \mathrm{CFU} / \mathrm{ml}$ of the bacterium were added to

6 all wells. The plates were then placed in a microplate spectrophotometer (PowerWave,

7 Biotek) set at $37^{\circ} \mathrm{C}$. The absorbance readings were taken at $600 \mathrm{~nm}$ every 30 minutes for

8 an 18 hours incubation period and kinetic curves were analysed.

\section{$10 \quad$ 2.3.3. Checkerboard Method}

11 The checkerboard method was performed using 96-well microtitre plates as described

12 previously (Moody, 2003; Schelz et al., 2006), to obtain the FIC index. The microplate 13 assay was arranged as follows: $\mathrm{EO}_{\mathrm{A}}$ was diluted two-fold along the $\mathrm{x}$-axis, whilst $\mathrm{EO}_{\mathrm{B}}$

14 was diluted two-fold along the y-axis. The final volume in each well was $100 \mu \mathrm{l}$

15 comprising $50 \mu \mathrm{l}$ of each EO dilution. Subsequently, $100 \mu$ l of media containing $2 \times 10^{6}$

$16 \mathrm{CFU} / \mathrm{ml}$ of the indicator strain were added to all wells. The plates were then incubated at

$1737^{\circ} \mathrm{C}$ for $18 \mathrm{~h}$. The FIC indices were calculated as $\mathrm{FIC}_{\mathrm{A}}+\mathrm{FIC}_{\mathrm{B}}$, where $\mathrm{FIC}_{\mathrm{A}}$ and $\mathrm{FIC}_{\mathrm{B}}$

18 are the minimum concentrations that inhibited the bacterial growth for EOs A and B,

19 respectively. Thus, FICs were calculated as follows: $\mathrm{FIC}_{\mathrm{A}}=\left(\mathrm{MIC}_{\mathrm{A}}\right.$ combination $/ \mathrm{MIC}_{\mathrm{A}}$

20 alone $)$ and $\mathrm{FIC}_{\mathrm{B}}=\left(\mathrm{MIC}_{\mathrm{B}}\right.$ combination $/ \mathrm{MIC}_{\mathrm{B}}$ alone $)$. The results were interpreted as

21 synergy $(\mathrm{FIC}<0.5)$, addition $(0.5 \leq \mathrm{FIC} \leq 1)$, indifference $(1<\mathrm{FIC} \leq 4)$ or antagonism

22 (FIC > 4). The concentrations used for oregano, marjoram and thyme, either alone or in

23 combination with the remainder of the EOs, are shown in Table 3. 
2 2.4.1. Food ingredients and $\mathrm{pH}$ assays

3 The effect of food ingredients and $\mathrm{pH}$ on the antimicrobial efficacy of EOs was

4 performed using a range of model media and Listeria monocytogenes IL323 as indicator

5 strain. The plant EOs were fixed factors: oregano $(30 \mathrm{ppm})$ and thyme $(60 \mathrm{ppm})$ were

6 independently assessed. Model media were comprised of the following: (i) water soluble

7 starch from potato (0, 1, 5 or $10 \%$, Sigma-Aldrich Ireland Ltd) in TSB; (ii) beef extract

$8(1.5,3,6$ or $12 \%$, Scharlau Chemie) in deionized water; and (iii) sunflower oil $(0,1,5$ or

9 10\%) in TSB. Model media containing starch or beef extract were autoclaved prior to use.

10 For the oil model media, the sunflower oil was autoclaved separately and then added to

11 sterile TSB. Filter-sterilized Tween 80 (Merck) was added at $0.1 \%$ to facilitate mixing

12 and to stabilize the emulsion. The $\mathrm{pH}$ of each model media was adjusted to 7.2. To

13 determine the effect of $\mathrm{pH}$ on EO efficacy TSB was adjusted to $\mathrm{pH} 4,5,6$ or 7 with $1 \mathrm{~N}$

$14 \mathrm{HCl}$ solution.

15 The growth of L. monocytogenes in each model medium with oregano or thyme was

16 monitored using 96 well-microplates. $200 \mu$ of each medium containing $2 \times 10^{6} \mathrm{CFU} / \mathrm{ml}$ of

17 the Listeria strain were added to wells of 96 well-microplates, which were assessed in

18 microplate spectrophotometer as described above. Positive controls contained model

19 media inoculated with the organism under investigation. Negative controls contained EOs

20 and sterile model media only. The survival curves of Listeria monocytogenes IL323 in

21 model media were monitored at $600 \mathrm{~nm}$ over a 24 hour period. 
2 The kinetic curves were analyzed by the KC4 software (Biotek) calculating the

3 increase in lag phase $(\lambda)$ and the maximum specific growth rate ( $\mu$ max). Statistical

4 analysis on data was performed using SPSS 15.0 (SPSS Inc., Chicago, U.S.A). Data

5 represents the means of experiments performed in duplicate and replicated at least twice.

6 Means were compared using ANOVA followed by LSD testing at $\mathrm{p}<0.05$ level.

\section{3. Results}

$9 \quad$ 3.1. Synergy studies

10 3.1.1. Spot on agar test and effect of varying concentrations on efficacy of EO 11 combinations

12 All the EO combinations were evaluated by the spot-on-agar-test. Only oregano in 13 combination with thyme showed a greater efficacy than when assessed individually 14 (results not shown). EO mixtures were also assessed monitoring the effect of varying 15 concentrations on E. coli (Table 2). Some combinations resulted in lag phase extensions 16 and reductions in the $\mu \max$ at half the concentrations of the individual EOs. The lag 17 phase duration of $E$. coli, when exposed to oregano in combination with basil, was 18 significantly increased by $7.44 \mathrm{~h}$ with respect to the increase recorded by oregano alone ( $\mathrm{p}$ $19<0.05)$. The combination of oregano with lemon balm resulted in a $3.55 \mathrm{~h}$ extension of

20 the lag phase by comparison with lemon balm alone. When oregano was combined with 21 marjoram, the reduction in the maximum specific growth rate achieved was 22 approximately 3 fold higher than that with the EOs alone $(\mathrm{p}<0.05)$. Combining oregano 23 with sage or thyme increased the lag phase of E. coli, by comparison with the individual 
1 EOs, but when oregano was combined with rosemary, there was no benefit compared to

2 the EOs alone.

$4 \quad$ 3.1.2. Checkerboard method

5 The quantitative effects of oregano, marjoram or thyme in combination with the other

6 EOs are described in terms of FIC indices. The FIC's of oregano in combination with the

7 other EOs are shown in Table 4. None of these combinations displayed a synergistic

8 activity against the bacteria used in this study. However, oregano combined with all the

9 other EOs had additive effects against $B$. cereus, but no additive or synergistic effects

10 were recorded for oregano based combinations against L. monocytogenes. The

11 combinations of oregano with marjoram and oregano with thyme had additive effects

12 against E. coli and P. aeruginosa, respectively, while oregano in combination with basil

13 had a useful additive activity against both Gram-negative organisms.

14 The FIC's for both marjoram and thyme combinations against L. monocytogenes are

15 shown in Table 5. A similar trend was noted for both EOs, where additive effects were

16 observed in combinations with basil, rosemary and sage.

18 3.2. Interaction with food ingredients and $\mathrm{pH}$

19 The lag phase $(\lambda)$ and the maximum specific growth rate $(\mu \max )$ of L. monocytogenes

20 IL323 grown in different model media are indicated in Tables 6 and 7, respectively. 


\subsubsection{Effect of protein}

2 To investigate the effect of proteins on the antimicrobial activity of oregano and

3 thyme, growth experiments with L. monocytogenes were performed in beef extract at 4

4 different concentrations (1.5, 3, 6, and 12\%). The lag phase of L. monocytogenes grown

5 in beef extract containing oregano was longer than the control at protein concentrations of

$6 \quad 6 \%$ and $12 \%(\mathrm{p}<0.05)$. The antimicrobial activity of thyme was increased in high

7 protein concentrations, leading to a significantly longer lag phase from $3 \%$ to $12 \%$ of

8 protein, with respect to the control $(\mathrm{p}<0.05)$. In the control culture, a longer lag phase

9 and a lower growth rate were observed at protein concentrations of $1.5 \%$ and $3 \%$ (p <

10 0.05). The growth rate of Listeria grown in beef extract with thyme was higher than the

11 control at protein concentrations of $3 \%$ and $6 \%(\mathrm{p}<0.05)$.

\section{3.2.2. Effect of starch}

14 Four different concentrations of potato starch $(0,1,5$ and $10 \%)$ were tested to

15 determine the influence of carbohydrates on the efficacy of oregano and thyme. The lag

16 phase of L. monocytogenes grown in starch model media containing oregano or thyme

17 decreased in either $5 \%$ or $10 \%$ starch concentration. Low concentrations of this

18 carbohydrate had a positive influence on the EO antimicrobial activity, with higher lag

19 phases by comparison with the control $(\mathrm{p}<0.05)$. In general, the growth rate of $L$.

20 monocytogenes decreased at higher starch concentrations. There was no significant

21 difference in the growth rate of Listeria within starch model media at any concentration

22 whether it contained EOs or not $(\mathrm{p}<0.05)$. 


\subsubsection{Effect of sunflower oil}

2 To assess the effect of oil on the EO antimicrobial activity, the growth of $L$.

3 monocytogenes was monitored in model media containing sunflower oil concentrations of

$4 \quad 0,1,5$ and 10\%. When EOs were included in the oil media, L. monocytogenes had a

5 shorter lag phase at higher oil concentrations $(\mathrm{p}<0.05)$. The growth rate decreased at

$610 \%$ oil. The addition of EOs to the varying concentrations of oil media did not

7 significantly effect the growth rate by comparison with controls.

9 3.2.4. Effect of $p H$

10 The effect of $\mathrm{pH}$ on the EO antimicrobial activity was evaluated using TSB at $\mathrm{pH} 4,5$,

116 and 7 (Tables 6, 7). L. monocytogenes did not grow at $\mathrm{pH}$ 4. The lag phase of Listeria

12 grown in $\mathrm{pH}$ model media with EO was longer than that recorded in EO free controls $(\mathrm{p}<$

13 0.05), especially at $\mathrm{pH} 5$, however, the lag phase was greatest at $\mathrm{pH} 5$ in control media

14 also. The growth rate of L. monocytogenes increased at higher $\mathrm{pH}$ values, regardless of 15 presence or absence of EOs.

\section{4. Discussion}

18 Since higher concentrations of plant EOs are generally required when added to

19 food, the application of EOs in food may be limited due to changes in organoleptic and

20 textural quality of food or interactions of EOs with food components (Devlieghere et al., 21 2004). Accordingly, a challenge for practical application of EOs is to develop optimised

22 low dose combinations to maintain product safety and shelf-life, thereby minimising the 
1 undesirable flavour and sensory changes associated with the addition of high

2 concentrations of EOs.

3 In this work, combinations of selected EOs (basil, lemon balm, marjoram, oregano,

4 rosemary, sage and thyme) were tested against B. cereus, E. coli, L. monocytogenes and

5 P. aeruginosa. Preliminary studies showed that the combination of oregano with thyme

6 had a greater efficacy than the EOs separately against the four pathogens. Furthermore,

7 the combinations of oregano with lemon balm and basil increased the lag phase of $E$. coli

8 by $3.55 \mathrm{~h}$ and $7.44 \mathrm{~h}$, respectively, by comparison with oregano alone. When oregano was

9 combined with marjoram, the maximum specific growth rate was reduced 3 times, with

10 respect to both EOs individually. There were important additive effects found when FIC

11 calculations from the extended study of oregano, marjoram and thyme in combination

12 with the remainder of the EOs were performed. Although none of the combinations

13 showed clear synergistic effects, combining EOs selected in this study, at lower

14 concentrations than required for the EOs alone, has potential for practical application to

15 extend the shelf-life of selected foods.

16 Burt (2004) suggested that the minor components present in the EOs extracts are more

17 critical to the activity than EOs main components mixed, and may have a synergistic

18 effect or potentiating influence. In many cases the result was an "additive effect". All the

19 oregano combinations were additive against B. cereus. The following EO combinations

20 also showed additive effects: oregano in combination with basil or thyme against $E$. coli

21 and $P$. aeruginosa, oregano combined with marjoram against $E$. coli, and marjoram and

22 thyme mixed with basil, rosemary or sage against L. monocytogenes. These results can be

23 explained considering the efficacy of the main components of EOs individually. In 
1 general, EOs possessing the strongest antibacterial properties contain a high percentage

2 of carvacrol and/or thymol, such as oregano or thyme (Elggayar et al., 2001; Dorman and

3 Deans, 2002; Burt, 2004; Oussalah et al., 2006). Since hydroxyl groups and allylic side

4 chains enhance EO efficacy (Burt, 2004), linalool and 4-thujanol, which are the main

5 components of basil and marjoram, respectively, may have contributed to the promising

6 antimicrobial activity achieved with their combinations. Previous studies reported the

7 high antimicrobial activity of linalool or basil against Gram-negative bacteria (Elggayar

8 et al., 2001; Oussalah et al., 2006). Acetate moieties in EO compounds may also

9 positively influence the activity of marjoram (Dorman and Deans, 2000). The main

10 components of rosemary and sage, which are camphor and eucalyptol, possess oxygen

11 functions in their structure and these functions are known to increase the antimicrobial

12 properties of terpenoids (Naigre et al., 1996) A major component of sage, $\beta$ -

13 caryophyllene, also has a high antimicrobial activity against Gram-positive bacteria

14 (Longaray Delamare et al., 2005). As antimicrobial activity depends not only on chemical

15 composition but also on lipophilic properties, the potency of functional groups or aqueous

16 solubility (Dorman and Deans, 2000) and the mixture of compounds with different

17 biochemical properties may increase EO efficacy.

18 However, the mechanism of action as well as EO composition deserves to be studied

19 in more detail in order to elucidate why combinations of EOs with a strong individual

20 antimicrobial efficacy such as oregano and thyme, did not show synergistic effects, and

21 why on the other hand combinations of two EOs with individually moderate activity

22 resulted in enhanced effects in combination, such as marjoram, basil, rosemary or sage.

23 Lambert et al., (2001), reported that carvacrol and thymol in combination were additive 
1 against $S$. aureus and $P$. aeruginosa. Nazer et al., (2004), found that thymol in

2 combination with other aromatic compounds led to improved inhibition, but no real

3 synergistic effect was demonstrated between compounds against Salmonella. As plant

4 EOs possess similar composition, their combinations may exhibit addition rather than a

5 synergistic effect. As a result, combinations with other compounds containing different

6 chemical structures may improve the EO efficacy. For example, synergism between

7 carvacrol and its precursor $p$-cymene has been noted (Ultee et al., 2000). It appears that $p$ -

8 cymene, a very weak antibacterial, swells bacterial cell membranes to a greater extent

9 than carvacrol does, so p-cymene probably enables carvacrol to be more easily

10 transported into the cell. Lin et al., (2004) reported a 1 Log cycle reduction of $L$.

11 monocytogenes using an oregano and cranberry EO combination (ratio, 75:25) and

12 although the reduction was $6 \log _{10} \mathrm{CFU}$ higher with the addition of lactic acid, the authors

13 suggested that synergistic effects did not occur with the EOs tested. Thus, EOs may be

14 employed in combination with other food preservation hurdles in order to control the

15 growth of pathogens and spoilage in food at low doses. In this context, some authors

16 proposed that the combination of essential oil constituents with other natural

17 preservatives, such as bacteriocins or fatty acids, promoted their efficiency against food-

18 borne pathogens (Yamazaki et al., 2004; Grande et al., 2007).

19 Recently, some studies have shown successful or potential applications of EOs and

20 their compounds, alone or in combination with other preservation methods, in order to

21 reduce or control the presence of foodborne pathogens and spoilage microorganisms on

22 food produce, such as fruit (Raybaudi-Massilia et al., 2006; Martinez-Romero et al., 23 2007), fish (Mahmoud et al., 2006), meat (Mytle et al., 2006; Ahn et al., 2007; Ghalfi et 
1 al., 2007; Solomakos et al., 2008), or milk (Cava et al., 2007). However, in some cases

2 the EO activity decreased considerably when added to a complex food system. For

3 example, Firouzi et al., (2007) found that oregano and nutmeg were effective against $E$.

4 coli $\mathrm{O} 157: \mathrm{H} 7$ in a broth system, but had no effect in ready-to-cook chicken. Uhart et al.,

5 (2005), also observed that when in direct contact, spices inactivated S. typhimurium

6 DT104, but that the activity decreased when applied to ground beef. Thus, an important

7 aspect for the optimised application of plant EOs is the evaluation of efficacy within food

8 products or in model systems that closely simulate food composition, prior to application

9 on real food. In this study four different model media were prepared to assess and

10 quantify the effect of food components on the antimicrobial efficacy of oregano and

11 thyme against L. monocytogenes.

12 The presence of high concentrations of protein promoted the growth of $L$.

13 monocytogenes, however the efficacy of oregano and thyme was also greater at these

14 higher concentrations of protein. The beef extract culture medium was constituted mainly

15 of peptones, which may have displayed hydrophobic properties with consequent

16 interactions with EOs to facilitate their dissolution in this medium. Baranauskien et al.,

17 (2006), reported that proteins usually possess a high binding capacity for flavor volatile

18 compounds. However, other studies have shown that milk proteins are limiting factors for

19 antimicrobial efficacy (Pol et al., 2001, Smith-Palmer et al., 2001, Devlieghere et al., 20 2004).

21 The antimicrobial activity of EOs was very high at $\mathrm{pH}$ 5. Previously, it was also

22 observed that the inhibitory effect of plant extracts was greater at acidic $\mathrm{pH}$ values (Del

23 Campo et al., 2000; Hsieh et al., 2001). The susceptibility of bacteria to EOs appears to 
1 increase with lower $\mathrm{pH}$ values since the hydrophobicity of EOs increases at low $\mathrm{pH}$,

2 consequently enabling easier dissolution in the lipids of the cell membrane of target

3 bacteria (Juven et al., 1994). The major efficacy of EOs at pH 5 was confirmed with the

4 lag phase and growth rate results for Listeria at this $\mathrm{pH}$, which were longer and lower,

5 respectively, than at $\mathrm{pH} 6$ or 7 . Similar trends with regard to $\mathrm{pH}$ effects were observed

6 within control media without EOs to those containing EOs. As the $\mathrm{pH}$ was reduced, the

7 lag phase increased and the growth rate declined for all tests. Furthermore, the addition of

8 either Oregano or Thyme, particularly to media at $\mathrm{pH} \mathrm{5,} \mathrm{enhanced} \mathrm{the} \mathrm{reduction} \mathrm{of} \mathrm{the}$

9 growth rate and the extension of the lag phase.

10 High concentrations of sunflower oil had a negative influence on the antimicrobial 11 activity of oregano and thyme EOs. Singh et al. (2003) reported that thyme EO reduced

12 bacterial populations significantly in zero- and low-fat hotdogs, but not in full-fat

13 hotdogs. Cava et al. (2007) found that the antimicrobial activity of cinnamon and clove

14 EOs against L. monocytogenes was reduced in milk samples with higher fat content.

15 Similarly, Smith-Palmer et al. (2001) observed that EOs were less effective in full-fat soft

16 cheese than in low-fat soft cheese. Canillac and Mourey (2004) also observed that the

17 addition of dairy fat into a test medium reduced the antilisterial efficacy of Picea excelsa

18 EO. Previously, mint oil was found to exhibit little antibacterial effect against $L$.

19 monocytogenes and S. enteritidis in high fat products, whereas in low fat food the same

20 EO was much more effective (Tassou et al., 1995). In this context, Glass and Johnson

21 (2004) reported that the antibotulinal effects of nisin and fatty acids were reduced by $20 \%$

22 milk fat or soybean oil. Mejlholm and Dalgaard (2002) suggested that if the EOs 
1 generally dissolve in the lipid phase there will be relatively less available to act on

2 bacteria present in the aqueous phase.

3 The EO efficacy was also reduced at high concentrations of starch, in contrast to the

4 general observation that carbohydrates in foods do not protect bacteria from the action of

5 EOs as much as fat and protein do (Shelef et al., 1984). Devlieghere et al. (2004) reported

6 a protective effect of carbohydrate for bacteria where starch at $30 \%$ had a negative impact

7 on the antimicrobial activity of chitosan. Ofman et al. (2004), also observed a negative

8 effect of tapioca starch on antimicrobial activity of preservatives.

9 Control of L. monocytogenes contamination, survival or growth in ready-to-eat (RTE)

10 meat is a major challenge confronting the food industry (Singh et al., 2003; Mytle et al.,

11 2006; Busatta et al., 2008). Organic acids, steam and hot water treatments are commonly

12 used as decontamination treatments, but $L$. monocytogenes can thrive in the environment

13 of meat processing facilities. Singh et al. (2003) suggested that the use of EOs in

14 conjunction with other preservation techniques such as chemical preservatives or low

15 temperature could develop a synergistic alternative to current methods. Based on the

16 results shown in this work, EO mixtures may be suitable for application within surface

17 decontamination protocols or inclusion as ingredients in ready to use raw or cooked

18 foods. This work shows a link between food composition and EO antimicrobial efficacy,

19 therefore careful selection of EO combinations taking food composition into account

20 prior to application development is important. Low dose combinations of EOs may be

21 useful for control of food safety in low fat RTE-meat based products where the sensory

22 characteristics could be desirable or in lower $\mathrm{pH}$ foods where a risk of pathogen survival 
1 exists. Incorporation of organic acids may also enhance the efficacy of EO combinations

2 for preservation of quality and safety in real food systems for extended periods.

\section{5. Conclusions}

5 The antimicrobial efficacy of the EOs in this study was found to be a function of

6 ingredient manipulation. The antimicrobial activity of oregano and thyme against $L$.

7 monocytogenes was increased at higher protein concentrations and moderately acidic $\mathrm{pH}$

8 conditions. Concentrations above 5\% of potato starch or sunflower oil reduced EO

9 efficacy. Therefore, the application of EOs should be further investigated for control of

10 microbial safety and spoilage concerns in proteinaceous foods and/or foods with low $\mathrm{pH}$

11 values, which may promote the antibacterial efficacy of EOs. The retention of anti-

12 microbial efficacy of EOs within suitable food systems should be evaluated alone as well

13 as taking hurdle effects of other preservation methods into account.

14 Combinations of plant EOs were assessed for synergistic activity, as this would allow

15 lower concentrations of EOs to be used, thereby achieving the twin aims of reducing any

16 undesirable organoleptic impact, as well as controlling food-borne pathogens and

17 spoilage bacteria in food. No synergy was found but addition occurred with a number of

18 combinations. Oregano and thyme were the most effective EOs applied individually, and

19 in combination they produced an additive effect against $B$. cereus and $P$. aeruginosa. The

20 combinations of oregano with marjoram and thyme with sage had promising efficacy

21 against $E$. coli and L. monocytogenes respectively. Thus, oregano combined with thyme

22 at low doses should be considered as a potential alternative for control of pathogens as

23 well as microbial spoilage issues, while the combinations of oregano with marjoram or 
1 thyme with sage might be useful for targeted control of key Gram-negative or Gram-

2 positive bacteria, respectively.

4 Acknowledgments

5 This work was supported by funding from Irish Department of Agriculture and Food as 6 part of the National Development Plan 2000-2006.

\section{References}

9 Ahn, J., Grün, I.U., Mustapha, A., 2007. Effects of plant extracts on microbial growth, 10 color change, and lipid oxidation in cooked beef. Food Microbiology 24, 7-14

11 Aureli, P., Costantini, A., Zolea, S., 1992. Antimicrobial activity of some plant essential 12 oils against Listeria monocytogenes. Journal of Food Protection 55 (5), 344-348.

13 Baranauskien, R., Venskutonis, P.R., Dewettinck, K., Verhe, R., 2006. Properties of 14 oregano (Origanum vulgare L.), citronella (Cymbopogon nardus G.) and marjoram (Majorana hortensis L.) flavors encapsulated into milk protein-based matrices. 16 Food Research International 39, 413-425.

17 Burt, S., 2004. Essential oils: their antibacterial properties and potential applications in 18 foods—a review. International Journal of Food Microbiology 94(3), 223-253.

19 Busatta C., Vidal, R.S., Popiolski, A.S., Mossi, A.J., Dariva, C., Rodrigues, M.R.A., 20 Corazza, F.C., Corazza, M.L., Vladimir Oliveira, J., Cansian, R.L., 2008. 21 Application of Origanum majorana L. essential oil as an antimicrobial agent in 22 sausage. Food Microbiology 25, 207-211. 
1 Canillac, N., Mourey, A., 2004. Effects of several environmental factors on the antiListeria monocytogenes activity of an essential oil of Picea excelsa. International Journal of Food Microbiology 92, 95- 103.

4 Cava, R., Nowak, E., Taboada, A., Marin-Iniesta, F., 2007. Antimicrobial activity of $5 \quad$ clove and cinnamon essential oils against Listeria monocytogenes in pasteurized 6 milk. Journal of Food Protection 70(12), 2757-2763.

7 Cintas, L.M., Casaus, P., Holo, H., Hernandez, P.E., Nes, I.F., Håvarstein, L.S., 1998.

11 Del Campo, J., Amito, M.J., Nguyen-The, C., 2000. Antimicrobial effect of rosemary extracts. Journal of Food Protection 63(10), 1359-1368.

13 Devlieghere, F., Vermeulen, A., Debevere, J., 2004. Chitosan: antimicrobial activity, interactions with food components and applicability as a coating on fruit and vegetables. Food Microbiology 21, 703-714.

Dorman, H. J. D., Deans, S.G., 2000. Antimicrobial agents from plants: antibacterial activity of plant volatile oils. Journal of Applied Microbiology 88, 308-316.

Elgayyar, M., Draughon F.A., Golden, D.A., Mount, J.R., 2001. Antimicrobial activity of essential oils from plants against selected pathogenic and saprophytic microorganisms. Journal of Food Protection 64(7), 1019-1024.

Firouzi, R., Shekarforoush, S.S., Nazer, A.H., Borumand, Z., Jooyandeh, A.R., 2007. Effects of essential oils of oregano and nutmeg on growth and survival of Yersinia 
3 Ghalfi, H., Benkerroum, N., Doguiet, D.D., Bensaid, M., Thonart, P., 2007. Effectiveness

4 of cell-adsorbed bacteriocin produced by Lactobacillus curvatus CWBI-B28 and

enterocolitica and Listeria monocytogenes in barbecued chicken. Journal of Food Protection 70(11), 2626-2630. selected essential oils to control Listeria monocytogenes in pork meat during cold storage. Letters in Applied Microbiology 44(3), 268-273.

Gill, A.O., Delaquis, P., Russo, P., Holley, R.A., 2002. Evaluation of antilisterial action of cilantro oil on vacuum packed ham. International Journal of Food Microbiology $73,83-92$.

Glass, K.A., Johnson, E.A., 2004. Antagonistic effect of fat on the antibotulinal activity of food preservatives and fatty acids. Food Microbiology 21, 675-682.

Grande, M.J., Lopez, R.L., Abriouel, H., Valdivia, E., Ben Omar, N., Maqueda, M., Martinez-Canamero, M., Galvez A., 2007. Treatment of vegetable sauces with enterocin AS-48 alone or in combination with phenolic compounds to inhibit proliferation of Staphylococcus aureus. Journal of Food Protection 70(2), 405-411.

Hammer, K. A., Carson, C. F., Riley, T.V., 1999. Antimicrobial activity of essential oils and other plant extracts. Journal of Applied Microbiology 86, 985-990. Holley, R. A., Patel, D., 2005. Improvement in shelf-life and safety of perishable foods by plant essential oils and smoke antimicrobials. Food Microbiology 22, 273-292.

Hsieh, P-C., Mau, J-L., Huang, S-H., 2001. Antimicrobial effect of various combinations of plant extracts. Food Microbiology 18, 35-43. 
1 Juven, B.J., Kanner, J., Schved, F., Weisslowicz, H., 1994. Factors that interact with the

2 antibacterial action of thyme essential oil and its active constituents. Journal of

3 Applied Bacteriology 76, 626-631

4 Lambert, R.J.W., Skandamis, P.N., Coote, P., Nychas, G.-J.E., 2001. A study of the

5 minimum inhibitory concentration and mode of action of oregano essential oil,

6 thymol and carvacrol. Journal of Applied Microbiology 91, 453-462.

7 Lin, Y. T., Labbe, R. G., Kalidas, S., 2004. Inhibition of Listeria monocytogenes in fish

8 and meat systems by use of Oregano and Cranberry phytochemical synergies.

$9 \quad$ Applied and Environmental Microbiology 70, 5672-5678.

10 Longaray Delamare, A. P., Moschen-Pistorello, I. T., Artico, L., Atti-Serafini, L.,

11 Echeverrigaray, S., 2005. Antibacterial activity of the essential oils of Salvia

12 officinalis L. and Salvia triloba L. cultivated in South Brasil. Food Chemistry $13 \quad 100(2), 603-608$.

14 Mahmoud B.S, Yamazaki, K., Miyashita, K., Kawai, Y., Shin, I.S., Suzuki, T., 2006.

15 Preservative effect of combined treatment with electrolyzed $\mathrm{NaCl}$ solutions and

16 essential oil compounds on carp fillets during convectional air-drying. International 17 Journal of Food Microbiology 106(3), 331-337.

18 Martínez-Romero, D., Guillén, F., Valverde, J.M., Bailén, G., Zapata, P., Serrano, M., 19 Castillo, S., Valero, D., 2007. Influence of carvacrol on survival of Botrytis cinerea 20 inoculated in table grapes. International Journal of Food Microbiology 115, 144$21 \quad 148$. 
1 Mejlholm, O., Dalgaard, P., 2002. Antimicrobial effect of essential oils on the seafood

2 spoilage micro-organism Photobacterium phosphoreum in liquid media and fish

3 products. Letters in Applied Microbiology 34, 27-31.

4 Moody, J.A. 2003. Synergism testing: broth microdilution checkerboard and broth 5 microdilution. In: Isenberg, H.D (Ed.), Clinical microbiology procedures handbook. 6 American Society for Microbiology, Washington, DC, pp. 1-28.

7 Mourey, A., Canillac, N., 2002. Anti-Listeria monocytogenes activity of essential oils 8 components of conifers. Food Control 13, 289- 292.

9 Mytle, N., Anderson, G.L., Doyle, M.P., Smith, M.A., 2006. Antimicrobial activity of 10 clove (Syzgium aromaticum) oil in inhibiting Listeria monocytogenes on chicken 11 frankfurters. Food Control 17 (2006) 102-107

12 Naigre, R., Kalck, P., Roques, C., Roux, I., Michel, G., 1996. Comparison of 13 antimicrobial properties of monoterpenes and their carbonylated products. Planta $14 \quad$ Medica 62, 275-277.

15 Nazer, A.I., Kobilinsky, A., Tholozana, J.-L., Dubois-Brissonneta, F., 2005. 16 Combinations of food antimicrobials at low levels to inhibit the growth of 17 Salmonella sv. Typhimurium: a synergistic effect?. Food Microbiology 22, 391$18 \quad 398$.

19 Ofman, M.H., Camposa, C.A., Gerschenson, L.N., 2004. Effect of preservatives on the 20 functional properties of tapioca starch: analysis of interactions. LWT Food Science $21 \quad$ and Technology 37, 355-361.

22 Oussalah, M., Caillet, S., Saucier, L., Lacroix, M., 2006. Inhibitory effects of selected 23 plant essential oils on the growth of four pathogenic bacteria: E. coli $\mathrm{O} 157: \mathrm{H} 7$, 
1 Salmonella Typhimurium, Staphylococcus aureus and Listeria monocytogenes.

$2 \quad$ Food Control 18(5), 414-420.

3 Pandit, V.A., Shelef, L.A., 1994. Sensitivity of Listeria monocytogenes to rosemary

4 (Rosmarinus officinalis L.). Food Microbiology 11, 57- 63.

5 Pol, I.E., Mastwijk, H.C., Slump, R.A., Popa, M.E., Smid, E.J., 2001. Influence of food

6 matrix on inactivation on Bacillus cereus by combinations of nisin, pulsed electric

7 field treatment and carvacrol. Journal of Food Protection 64(7), 1012-1018.

8 Raybaudi-Massilia, R.M., Mosqueda-Melgar, J., Martín-Belloso, O., 2006. Antimicrobial

9 activity of essential oils on Salmonella enteritidis, Escherichia coli, and Listeria

10 innocua in fruit juices. Journal of Food Protection 69(7), 1579-1586.

11 Schelz, Z., Molnar, J., Hohmann, J., 2006. Antimicrobial and antiplasmid activities of 12 essential oils. Fitoterapia 77, 279-285.

13 Shelef, L.A., Jyothi, E.K., Bulgarelli, M.A., 1984. Growth of enteropathogenic and 14 spoilage bacteria in sage-containing broth and foods. Journal of Food Science 49 $15 \quad(737-740), 809$.

16 Singh, A. Singh, R.K, Bhunia, A.K., Singh, N., 2003. Efficacy of plant essential oils as 17 antimicrobial agents against Listeria monocytogenes in hotdogs. LWT Food Science 18 and Technology, 36, 787-794.

19 Smith-Palmer, A., Stewart, J., Fyfe., L., 1998. Antimicrobial properties of plant essential 20 oils and essences against five important food-borne pathogens. Letters in Applied $21 \quad$ Microbiology 26, 118-122.

22 Smith-Palmer, A., Stewart, J., Fyfe., L., 2001. The potential application of plant essential 23 oils as natural food preservatives in soft cheese. Food Microbiology 18, 463-470. 
1 Solomakos, N., Govaris, A., Koidis, P., Botsoglou, N., 2008. The antimicrobial effect of

2 thyme essential oil, nisin, and their combination against Listeria monocytogenes in

3 minced beef during refrigerated storage. Food Microbiology, 25(1):120-127.

4 Tassou, C., Drosinos, E.H., Nychas, G.-J.E., 1995. Effects of essential oil from mint 5 (Mentha piperita) on Salmonella enteritidis and Listeria monocytogenes in model 6 food systems at $4^{\circ} \mathrm{C}$ and $10^{\circ} \mathrm{C}$. Journal of Applied Bacteriology 78, 593- 600 .

7 Uhart, M., Maks, N., Ravishankar, S., 2006. Effect of spices on growth and survival of 8 Salmonella typhimurium DT 104 in ground beef stored at 4 and 8C. Journal of Food $9 \quad$ Safety $26(2), 115-125$.

10 Ultee, A., Kets, E.P.W., Alberda, M., Hoekstra, F.A., Smid, E.J., 2000. Adaptation of the 11 food-borne pathogen Bacillus cereus to carvacrol. Archives of Microbiology 174 $12 \quad(4), 233-238$.

13 Yamazaki, K., Yamamoto, T., Kawai, Y., Inoue, N., 2004. Enhancement of antilisterial 14 activity of essential oils constituents by nisin and diglycerol fatty acid ester. Food $15 \quad$ Microbiology 21, 283-289 
Table 1

Essential oils selected for this study

\begin{tabular}{|c|c|c|}
\hline Essential oil & Scientific name & Main components (\%) \\
\hline Basil & Ocimum basilicum & $\begin{array}{l}\text { Linalool }(42.3) \\
\text { Estragole }(26.9) \\
\text { Eucalyptol }(8.1)\end{array}$ \\
\hline Lemon balm & Melissa officinalis & $\begin{array}{l}\text { Citral (Neral/Geranial) }(22.4 / 36.7) \\
\text { Caryophyllene (13.2) }\end{array}$ \\
\hline Marjoram & Origanum majorana & $\begin{array}{l}\text { 4-Thujanol (36.2) } \\
\text { Sabinene hydrate acetate (16.8) } \\
\text { Terpinene-4-ol (8.7) }\end{array}$ \\
\hline Oregano & Origanum vulgare & $\begin{array}{l}\text { Carvacrol (68.5) } \\
\text { Thymoquinone (12.1) } \\
\text { p-Cymene (7.8) }\end{array}$ \\
\hline Rosemary & Rosmarinus officinalis & $\begin{array}{l}\text { Eucalyptol (39.6) } \\
\text { Camphor (19) } \\
\text { Alpha Pinene (4.8) }\end{array}$ \\
\hline Sage & Salvia triloba & $\begin{array}{l}\text { Eucalyptol (42.0) } \\
\text { Camphor (12.0) } \\
\text { Caryophyllene (7.2) }\end{array}$ \\
\hline Thyme & Thymus vulgaris & $\begin{array}{l}\text { Thymol (52.9) } \\
\text { p-Cymene (34.0) }\end{array}$ \\
\hline
\end{tabular}


Table 2

Effect of EO combinations on growth parameters of E. coli ATCC 25922

\begin{tabular}{|c|c|c|c|c|c|}
\hline \multicolumn{2}{|l|}{ EOs (Individual) } & \multicolumn{2}{|c|}{ Lag phase $^{a}$} & \multicolumn{2}{|c|}{$\begin{array}{l}\text { Maximum specific } \\
\text { growth rate }^{b}\end{array}$} \\
\hline Oregano & $300 \mathrm{ppm}$ & 3.84 & $\begin{array}{l}\text { St. Dev. } \\
\pm 0.21\end{array}$ & 0.367 & $\begin{array}{l}\text { St. Dev. } \\
\pm 0.042\end{array}$ \\
\hline Basil & $10,000 \mathrm{ppm}$ & 4.86 & \pm 0.30 & 0.452 & \pm 0.005 \\
\hline Lemon balm & $20,000 \mathrm{ppm}$ & 5.21 & \pm 0.43 & 0.401 & \pm 0.019 \\
\hline Marjoram & $2,000 \mathrm{ppm}$ & 3.77 & \pm 1.01 & 0.406 & \pm 0.021 \\
\hline Rosemary & $10,000 \mathrm{ppm}$ & 4.55 & \pm 0.70 & 0.480 & \pm 0.196 \\
\hline Sage & $50,000 \mathrm{ppm}$ & 4.80 & \pm 1.61 & 0.432 & \pm 0.016 \\
\hline Thyme & 600 ppm & 3.29 & \pm 0.07 & 0.400 & \pm 0.006 \\
\hline
\end{tabular}

EO combinations ${ }^{\mathrm{c}}$

$\begin{array}{lcrcccc}\text { Oregano + Basil } & (1 / 2) & 11.28 & \pm 3.05 & 0.452 & \pm 0.004 \\ \text { Oregano + Basil } & (1 / 4) & 4.21 & \pm 0.19 & 0.449 & \pm 0.004 \\ \text { Oregano + Lemon balm }(1 / 2) & 8.76 & \pm 0.18 & 0.312 & \pm 0.023 \\ \text { Oregano + Lemon balm }(1 / 4) & 5.69 & \pm 0.18 & 0.407 & \pm 0.015 \\ \text { Oregano + Marjoram } & (1 / 2) & 4.05 & \pm 1.23 & 0.117 & \pm 0.043 \\ \text { Oregano + Marjoram } & (1 / 4) & 2.86 & \pm 0.34 & 0.404 & \pm 0.032 \\ \text { Oregano + Rosemary } & (1 / 2) & 5.84 & \pm 1.37 & 0.383 & \pm 0.018 \\ \text { Oregano + Rosemary } & (1 / 4) & 3.76 & \pm 0.81 & 0.420 & \pm 0.006 \\ \text { Oregano + Sage } & (1 / 2) & 8.50 & \pm 1.25 & 0.419 & \pm 0.019 \\ \text { Oregano + Sage } & (1 / 4) & 4.67 & \pm 0.51 & 0.425 & \pm 0.005 \\ \text { Oregano + Thyme } & (1 / 2) & 6.32 & \pm 0.57 & 0.376 & \pm 0.025 \\ \text { Oregano + Thyme } & (1 / 4) & 3.08 & \pm 0.17 & 0.395 & \pm 0.009\end{array}$

\footnotetext{
${ }^{\mathrm{a}}$ Lag phase is expressed in hours.

${ }^{\mathrm{b}}$ Maximum specific growth rate is expressed in hours ${ }^{-1}$.

${ }^{\mathrm{c}}$ EO combinations were assessed at $50 \%(1 / 2)$ and $25 \%(1 / 4)$ of the individual concentrations.
} 
Table 3

Concentrations $^{\mathrm{a}}$ of EOs used alone (A) or in combination (C) against the bacteria selected for this study

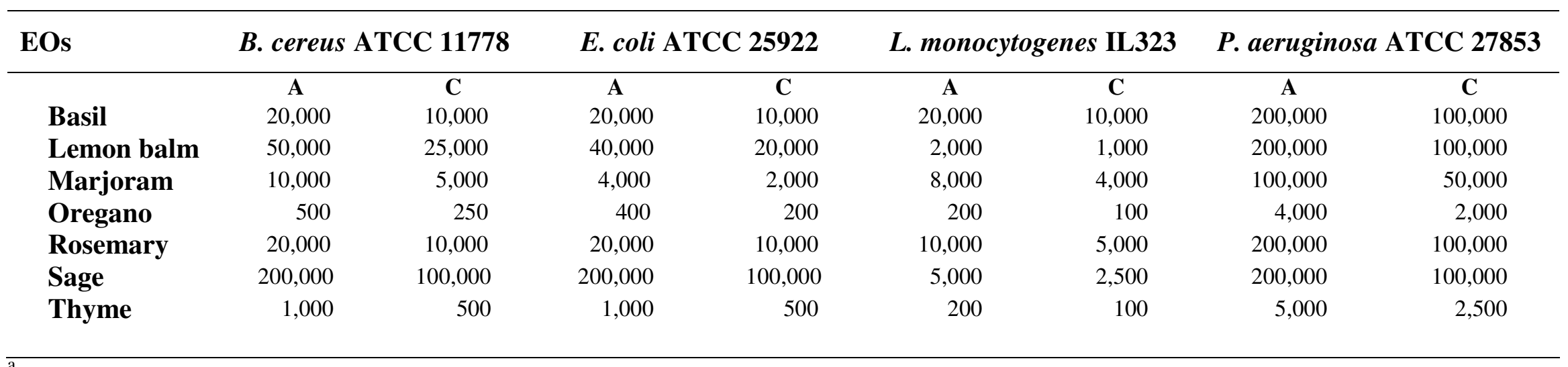

${ }^{\mathrm{a}}$ Concentrations are expressed in ppm 
Table 4

FIC indices of oregano combinations

\begin{tabular}{|c|c|c|c|c|c|c|c|c|}
\hline \multirow{2}{*}{ Combinations } & \multicolumn{2}{|c|}{ B. cereus ATCC 11778} & \multicolumn{2}{|c|}{ E. coli ATCC 25922} & \multicolumn{2}{|c|}{ L. monocytogenes IL323 } & \multicolumn{2}{|c|}{ P. aeruginosa ATCC 27853} \\
\hline & FIC & Stdev $^{b}$ & FIC & Stdev $^{\mathrm{b}}$ & FIC & $\operatorname{Stdev}^{\mathrm{b}}$ & FIC & $\operatorname{Stdev}^{\mathrm{b}}$ \\
\hline \multicolumn{9}{|l|}{ Oregano + } \\
\hline Basil & $0.83(\mathrm{~A})^{\mathrm{a}}$ & \pm 0.14 & $1.00(\mathrm{~A})$ & \pm 0.00 & $1.25(\mathrm{I})$ & \pm 0.35 & $1.00(\mathrm{~A})$ & \pm 0.00 \\
\hline Lemon balm & $0.86(\mathrm{~A})$ & \pm 0.18 & $1.17(\mathrm{I})$ & \pm 0.34 & $1.25(\mathrm{I})$ & \pm 0.43 & $1.38(\mathrm{I})$ & \pm 0.12 \\
\hline Marjoram & $0.75(\mathrm{~A})$ & \pm 0.15 & $0.83(\mathrm{~A})$ & \pm 0.30 & $1.18(\mathrm{I})$ & \pm 0.40 & $1.75(\mathrm{I})$ & \pm 0.35 \\
\hline Rosemary & $0.79(\mathrm{~A})$ & \pm 0.20 & $1.83(\mathrm{I})$ & \pm 0.29 & $1.50(\mathrm{I})$ & \pm 0.00 & $1.50(\mathrm{I})$ & \pm 0.00 \\
\hline Sage & $1.00(\mathrm{~A})$ & \pm 0.00 & $1.38(\mathrm{I})$ & \pm 0.18 & $1.75(\mathrm{I})$ & \pm 0.35 & $1.50(\mathrm{I})$ & \pm 0.00 \\
\hline Thyme & $0.78(\mathrm{~A})$ & \pm 0.16 & $1.17(\mathrm{I})$ & \pm 0.30 & $1.18(\mathrm{I})$ & \pm 0.30 & $0.88(\mathrm{~A})$ & \pm 0.18 \\
\hline
\end{tabular}


Table 5

FIC indices of marjoram and thyme combinations against L. monocytogenes IL323

\begin{tabular}{|c|c|c|c|c|}
\hline \multirow{2}{*}{ Combinations } & \multicolumn{2}{|c|}{ Marjoram } & \multicolumn{2}{|c|}{ Thyme } \\
\hline & FIC & Stdev $^{b}$ & FIC & Stdev $^{b}$ \\
\hline \multicolumn{5}{|c|}{ Marjoram or thyme + } \\
\hline Basil & $0.75(\mathrm{~A})^{\mathrm{a}}$ & \pm 0.51 & $0.94(\mathrm{~A})$ & \pm 0.44 \\
\hline Lemon balm & $1.25(\mathrm{I})$ & \pm 0.00 & $1.25(\mathrm{I})$ & \pm 0.35 \\
\hline Marjoram & - & & $1.55(\mathrm{I})$ & \pm 0.57 \\
\hline Oregano & $1.18(\mathrm{I})$ & \pm 0.40 & $1.18(\mathrm{I})$ & \pm 0.30 \\
\hline Rosemary & $1.03(\mathrm{~A})$ & \pm 0.54 & $1.06(\mathrm{~A})$ & \pm 0.62 \\
\hline Sage & $1.00(\mathrm{~A})$ & \pm 0.25 & $1.00(\mathrm{~A})$ & \pm 0.00 \\
\hline Thyme & $1.55(\mathrm{I})$ & \pm 0.57 & & - \\
\hline
\end{tabular}

$\overline{{ }^{a}}$ Results are interpreted as synergy $(\mathbf{S}$, FIC $<0.5)$, addition $(\mathbf{A}, 0.5 \leq$ FIC $\leq 1)$, indifference $(\mathbf{I}, 1<$ FIC $\leq 4)$ or antagonism (AN, FIC > 4).

${ }^{\mathrm{b}}$ Standard deviation 
Table 6

Lag phase $(\lambda)$ of L. monocytogenes IL323 grown in model media containing oregano (30 ppm) or thyme (60 ppm)

\begin{tabular}{|c|c|c|c|c|c|c|}
\hline \multirow[t]{2}{*}{ Model media } & \multicolumn{2}{|c|}{ Oregano } & \multicolumn{2}{|c|}{ Thyme } & \multicolumn{2}{|c|}{ Control $^{\mathrm{c}}$} \\
\hline & $\lambda(\mathrm{h})^{\mathrm{a}}$ & Stdev $^{b}$ & $\lambda(\mathrm{h})^{\mathrm{a}}$ & Stdev & $\lambda(\mathrm{h})^{\mathrm{a}}$ & Stdev \\
\hline \multicolumn{7}{|l|}{ Beef extract } \\
\hline $1.5 \%$ & 7.39 & \pm 0.96 & 9.15 & \pm 2.57 & 8.01 & \pm 2.63 \\
\hline $3.0 \%$ & 7.81 & \pm 1.22 & 11.79 & \pm 1.33 & 6.14 & \pm 0.08 \\
\hline $6.0 \%$ & 10.75 & \pm 2.31 & 10.94 & \pm 2.51 & 6.48 & \pm 0.20 \\
\hline $12.0 \%$ & 10.79 & \pm 1.53 & 9.75 & \pm 2.16 & 6.33 & \pm 0.37 \\
\hline \multicolumn{7}{|l|}{ Starch media } \\
\hline $0.0 \%$ & 15.01 & \pm 1.40 & 12.06 & \pm 2.70 & 7.80 & \pm 0.93 \\
\hline $1.0 \%$ & 13.96 & \pm 3.66 & 11.69 & \pm 2.08 & 7.04 & \pm 0.17 \\
\hline $5.0 \%$ & 9.71 & \pm 0.89 & 8.87 & \pm 3.56 & 7.58 & \pm 0.30 \\
\hline $10.0 \%$ & 8.84 & \pm 1.52 & 8.43 & \pm 2.38 & 8.04 & \pm 0.75 \\
\hline \multicolumn{7}{|c|}{ Sunflower oil media } \\
\hline $0.0 \%$ & 15.23 & \pm 0.05 & 15.05 & \pm 0.45 & 7.75 & \pm 0.13 \\
\hline $1.0 \%$ & 14.21 & \pm 0.33 & 12.54 & \pm 0.06 & 7.31 & \pm 0.10 \\
\hline $5.0 \%$ & 10.50 & \pm 0.13 & 9.22 & \pm 0.30 & 7.24 & \pm 0.10 \\
\hline $10.0 \%$ & 9.17 & \pm 0.14 & 9.47 & \pm 0.03 & 7.33 & \pm 0.18 \\
\hline \multicolumn{7}{|l|}{ pH } \\
\hline TSB pH 4 & 0.00 & \pm 0.00 & 0.00 & \pm 0.00 & 0.00 & \pm 0.00 \\
\hline TSB pH 5 & 12.43 & \pm 0.44 & 16.13 & \pm 1.28 & 9.55 & \pm 1.83 \\
\hline TSB pH 6 & 7.70 & \pm 0.73 & 9.48 & \pm 1.51 & 6.75 & \pm 1.57 \\
\hline TSB pH 7 & 9.50 & \pm 0.09 & 10.80 & \pm 0.95 & 6.88 & \pm 1.10 \\
\hline
\end{tabular}

\footnotetext{
${ }^{\mathrm{a}}$ Lag phase is expressed in hours.

${ }^{\mathrm{b}}$ Standard deviations are indicated beside each value.

${ }^{\mathrm{c}}$ L. monocytogenes grown in model media without any EO was used as the control.
} 
Table 7

Maximum specific growth rate ( $\mu$ max) of L. monocytogenes IL323 grown in model media containing oregano $(30 \mathrm{ppm})$ or thyme $(60 \mathrm{ppm})$

\begin{tabular}{|c|c|c|c|c|c|c|}
\hline \multirow[t]{2}{*}{ Model media } & \multicolumn{2}{|c|}{ Oregano } & \multicolumn{2}{|c|}{ Thyme } & \multicolumn{2}{|c|}{ Control $^{\mathrm{c}}$} \\
\hline & $\mu \max \left(h^{-1}\right)^{a}$ & Stdev $^{b}$ & $\mu \max \left(\mathrm{h}^{-1}\right)^{\mathrm{a}}$ & Stdev & $\mu \max \left(\mathrm{h}^{-1}\right)^{\mathrm{a}}$ & Stdev \\
\hline \multicolumn{7}{|l|}{ Beef extract } \\
\hline $1.5 \%$ & 0.034 & \pm 0.006 & 0.079 & \pm 0.022 & 0.054 & \pm 0.037 \\
\hline $3.0 \%$ & 0.076 & \pm 0.041 & 0.146 & \pm 0.077 & 0.074 & \pm 0.013 \\
\hline $6.0 \%$ & 0.099 & \pm 0.037 & 0.195 & \pm 0.068 & 0.117 & \pm 0.032 \\
\hline $12.0 \%$ & 0.195 & \pm 0.018 & 0.200 & \pm 0.019 & 0.215 & \pm 0.001 \\
\hline \multicolumn{7}{|l|}{ Starch media } \\
\hline $0.0 \%$ & 0.185 & \pm 0.058 & 0.250 & \pm 0.021 & 0.238 & \pm 0.040 \\
\hline $1.0 \%$ & 0.208 & \pm 0.082 & 0.271 & \pm 0.014 & 0.268 & \pm 0.058 \\
\hline $5.0 \%$ & 0.142 & \pm 0.032 & 0.164 & \pm 0.020 & 0.147 & \pm 0.008 \\
\hline $10.0 \%$ & 0.098 & \pm 0.016 & 0.104 & \pm 0.003 & 0.097 & \pm 0.002 \\
\hline \multicolumn{7}{|c|}{ Sunflower oil media } \\
\hline $0.0 \%$ & 0.240 & \pm 0.015 & 0.231 & \pm 0.008 & 0.279 & \pm 0.008 \\
\hline $1.0 \%$ & 0.226 & \pm 0.001 & 0.209 & \pm 0.004 & 0.223 & \pm 0.007 \\
\hline $5.0 \%$ & 0.208 & \pm 0.012 & 0.235 & \pm 0.005 & 0.200 & \pm 0.018 \\
\hline $10.0 \%$ & 0.174 & \pm 0.013 & 0.220 & \pm 0.004 & 0.170 & \pm 0.014 \\
\hline \multicolumn{7}{|l|}{ pH } \\
\hline TSB pH 4 & 0.000 & \pm 0.000 & 0.000 & \pm 0.000 & 0.000 & \pm 0.000 \\
\hline TSB pH 5 & 0.004 & \pm 0.001 & 0.016 & \pm 0.006 & 0.017 & \pm 0.018 \\
\hline TSB pH 6 & 0.141 & \pm 0.020 & 0.175 & \pm 0.025 & 0.173 & \pm 0.064 \\
\hline TSB pH 7 & 0.284 & \pm 0.022 & 0.328 & \pm 0.011 & 0.261 & \pm 0.054 \\
\hline
\end{tabular}

\footnotetext{
${ }^{a}$ Maximum specific growth rate is expressed in hours $^{-1}$.

${ }^{\mathrm{b}}$ Standard deviations are indicated beside each value.

${ }^{\mathrm{c}}$ L. monocytogenes grown in model media without any EO was used as the control.
} 